\title{
Epigenetic Mechanisms in Early Mammalian Development
}

\author{
D. Solter, ${ }^{*}$ T. HiIRagi, ${ }^{*}$ A.V. Evsikov, ${ }^{\dagger}$ J. Moyer, ${ }^{\dagger}$ W.N. De VRIES, ${ }^{\dagger}$ \\ A.E. Peaston ${ }^{\dagger}$ AND B.B. Knowles ${ }^{\dagger}$ \\ ${ }^{*}$ Max-Planck Institute of Immunobiology, 79108 Freiburg, Germany; ${ }^{\dagger}$ The Jackson Laboratory, \\ Bar Harbor, Maine 04609
}

In one sense, development of multicellular organisms begins well before fertilization because the molecules and controlling mechanisms that direct early development are put in place during oogenesis. The informational content of a mammalian egg at fertilization is not only restricted to its DNA sequence, but also to various DNA and chromatin modifications, specific macromolecules (RNAs and proteins), and possibly the characteristic architecture of the cytoplasm and plasma membrane. These sources of stored, necessary information can be viewed as epigenetic controlling mechanisms (Fig. 1). In the ensuing text we will briefly touch on these subjects, delineating what is presently known about them and, more important, what still remains to be elucidated. The literature on these subjects is vast and space restrictions prevent us from citing each relevant paper, for which we apologize.

\section{DNA, CHROMATIN, AND IMPRINTING}

The egg and sperm genomes are transcriptionally inactive: The DNA is highly methylated, and the chromatin components, histones and protamines, are modified to ensure heterochromatization (Li 2002; Grewal and Moazed 2003; Reik et al. 2003). To secure the activation of the embryonic genome essential for further development, this must change. Upon fertilization the paternal genome undergoes rapid demethylation (Santos et al. 2002), followed by gradual demethylation of the maternal genome (Santos et al. 2002; Reik et al. 2003). The basis for this

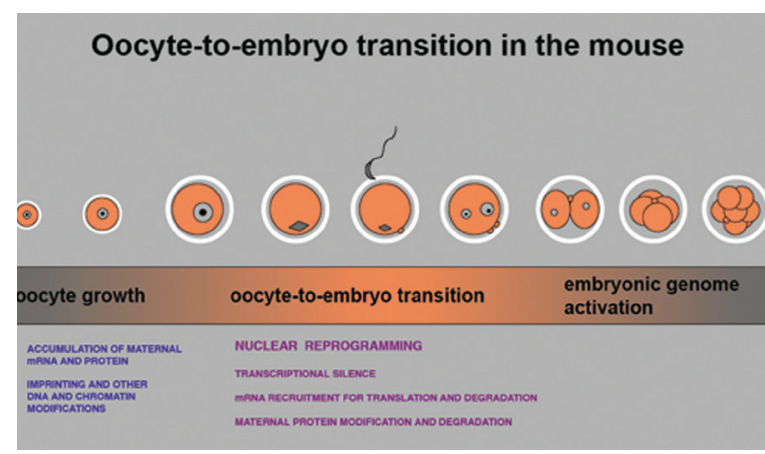

Figure 1. Oocyte-to-embryo transition in the mouse. Relevant events occurring during oocyte growth and during the oocyte-toembryo transition, which are discussed in this paper.

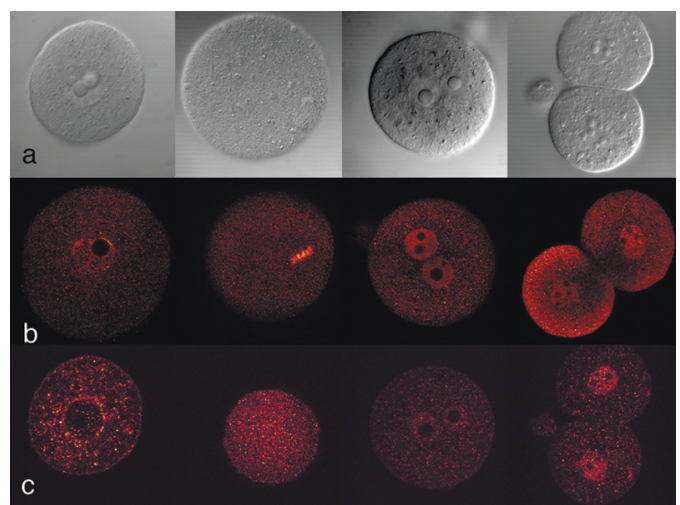

Figure 2. In the same development stages, $(a)$ a differential interference contrast (DIC) image of fully grown oocyte, ovulated oocyte, zygote, and two-cell-stage embryo; $(b)$ distribution of histone $\mathrm{H} 3$ monomethylated at lysine 9 as detected by immunofluorescence (Abcam, cat \# ab9045, rabbit polyclonal antibody); and (c) localization of Polycomb group protein Suppressor of Zeste 12 (Upstate, cat \# 07-379, rabbit immunoaffinity purified $\operatorname{IgG})$.

differential DNA demethylation is not entirely clear, although it may be related to the observed differences in histone $\mathrm{H} 3$ methylation patterns.

Histone $\mathrm{H} 3$ when methylated at lysine 9 (H3/K9) marks heterochromatin and is present in high amounts in the germinal vesicle (Fig. 2b). In the fertilized egg, histone $\mathrm{H} 3 / \mathrm{K} 9$ is prominent in the female pronucleus but less abundant or absent in the male pronucleus (Reik et al. 2003; Liu et al. 2004). The difference between male- and female-derived chromatin persists into the two-cell-stage embryo (Fig. 2b) (Liu et al. 2004), but is no longer detectable by the four-cell-stage embryo. Changes in methylation of histone $\mathrm{H} 3$ are regulated by histone methyltransferase activity and it is thus interesting to note that Suppressor of Zeste 12 (SUZ12) is detectable in pronuclei of the late, but not early, zygote and its abundance in the nucleus appears to increase in the two-cell stage (Fig. 2c). Suz 12 mRNA is an abundant transcript in the two-cell-stage mouse embryos (Evsikov et al. 2004), and human SUZ12 is part of a multiprotein complex together with the histone methyltransferase specific for lysine 9 (and lysine 27) of $\mathrm{H} 3$ histone (Kuzmichev et al. 2002). It is thus possible that de novo methylation of $\mathrm{H} 3$ 
histones in cleavage-stage embryos is mediated by a similar complex. Egg chromatin is also associated with a specific form of $\mathrm{H} 1$ linker histone, known as oocyte-specific H1FOO (Gao et al. 2004; Teranishi et al. 2004), which is slowly replaced by somatic $\mathrm{H} 1$ histone during cleavage. It is not clear how much this change contributes to the activation of the embryonic genome.

The observed differences in DNA and histone methylation between the paternal and maternal genomes (Reik et al. 2003) may have significant developmental consequences, or they could be developmentally irrelevant. Sperm chromatin is stripped of protamines soon after fertilization; therefore, its earlier DNA demethylation could simply reflect easier access to the denuded DNA. Examination of the timing of DNA demethylation following nuclear transfer of round spermatids or spermatocytes, both of which are devoid of protamines but compatible with normal development, would be informative in this respect.

Aside from the possible global differences between the paternal and maternal genome, imprinting is another epigenetic mechanism that leads to a long-term difference in expression of specific genes. During gametogenesis, imprinting imposes a mark on certain genes so that, following fertilization and into the adult, imprinted genes are expressed either from the maternal or paternal allele alone. The presence of numerous genes in the hemizygous state, in terms of expression, obviously poses certain genetic risks, which are presumably balanced by as yet unidentified gains. For our present discussion it is sufficient to say that interference with imprinting can lead to significant developmental disturbances (Reik and Walter 2001a; Kaneko-Ishino et al. 2003), and that imprinting is essential for normal development (McGrath and Solter 1984; Surani et al. 1984).

Despite extensive work, the exact molecular mechanism of imprinting is not known, though methylation of specific DNA sequences associated with imprinted genes clearly plays a role (Reik and Walter 2001a; KanekoIshino et al. 2003). Not all imprinted genes are regulated in the same way, and several different and complex mechanisms have been described (Reik and Walter 2001a; Kaneko-Ishino et al. 2003). Methylation of a specific region as a functioning imprint is much more common in the maternal genome, regardless of whether the imprinted gene is expressed maternally or paternally. Because the paternal genome is subject to drastic early demethylation, it has been hypothesized that the preponderance of methylation imprints in the maternal genome evolved to protect imprinting marks from this early demethylation (Reik and Walter 2001b). Although imprinting plays an important role in mammalian development, and its dysfunction may be instrumental in several pathological states, its exact purpose and evolution is not clear and is the subject of much speculation (Wilkins and Haig 2003).

\section{TRANSCRIPTION AND TRANSCRIPTIONAL CONTROL}

Several mechanisms can account for the transcriptional silence of mature gametes. In mammals activation of the embryonic genome per se occurs in the cleavage stages but in the mouse some signs of transcription have been observed in the late zygote (Bouniol et al. 1995). Several approaches have been described to explore the changes in gene expression, which occur between the end of oocyte growth and completion of preimplantation development. All the methods described thus far rely on the presence, absence, increase, or decrease of mRNAs. One should bear in mind that, depending on the method used, these changes do not necessarily reflect a change in transcription.

We prepared and analyzed cDNA libraries representing different stages of preimplantation development (Rothstein et al. 1992). After sequencing randomly picked clones and clustering the expressed sequence tags, we were able to determine the nature and abundance of mRNAs present at a specific developmental stage (Evsikov et al. 2004). A similar approach has been used recently to compare the transcriptomes of preimplantation and postimplantation embryos and several stem cell lines (Sharov et al. 2003). Microarray analysis of global genome activity during preimplantation development has also been accomplished (Hamatani et al. 2004; Wang et al. 2004). Despite possible technical limitations and the problems of interpretation, these approaches do provide a first global insight into the molecular anatomy of early embryos. These studies will serve as a source of information to identify and analyze the expression, and eventually the function, of individual genes. Because significant increases and decreases in the abundance of individual mRNAs have been observed in this period when there is supposedly no transcription, and because these abundance levels change in the presence of inhibitors of RNA polymerase II (Hamatani et al. 2004; Wang et al. 2004), other mechanisms besides transcription of normal host genes are obviously at work. This brings us to the issue of mRNA metabolism, utilization, and controlled translation.

\section{TRANSLATIONAL CONTROL}

Transcriptional silence lasts about 48 hours in the mouse and in humans it is presumably longer. Although some mRNAs may be delivered by the sperm (Ostermeier et al. 2004), egg maturation, completion of meiosis, remodeling of sperm and egg genomes, and activation of embryonic genome are based on stored maternal mRNAs and proteins. Translation of stored mRNAs and their degradation can provide a rapid and timely response to the demand for a specific gene product without activating the transcriptional machinery. Indeed, controlled translation is a preferred molecular control mechanism in the oocyte-to-embryo transition and in the nervous system (Darnell 2002). In addition to controlled translation of stored maternal mRNA there is also the option for localization of maternal mRNAs in the egg, which has been extensively explored during amphibian and fruit fly development (Richter 1999; Solter and Knowles 1999; Stebbins-Boaz et al. 1999; van Eeden and St Johnston 1999; Darnell 2002).

The mechanism, which first masks and then activates maternal mRNA translation in the mouse egg, was initially suggested for tissue-type plasminogen activator and 
involves polyadenylation of the mRNA resulting in protein synthesis (Strickland et al. 1988). Subsequently, controlled translation of numerous genes during the period of transcriptional silence was described and may be of significant importance to the control of gene expression during the oocyte-to-embryo transition (Oh et al. 2000; Solter et al. 2002; Knowles et al. 2003). Very briefly, specific sequences found in the 3 'UTR of certain mRNA species bind proteins, which protect them from degradation and translation. One of these 3'UTR sequences, the cytoplasmic polyadenylation element (CPE), binds a protein, CPEB, which in turn interacts with a protein complex containing maskin, localized at the 5'UTR end of the mRNA (Stebbins-Boaz et al. 1999). On initiation of oocyte maturation CPEB becomes phosphorylated, destabilizing the complex and allowing the mRNA to be polyadenylated, translated, and degraded (Hodgman et al. 2001). CPEB null-mutant mice are unable to make functional gametes because of the lack of formation of a synaptonemal complex (Tay and Richter 2001). Mice, bearing alleles of CPEB that can be conditionally mutated in the oocyte, should be employed to determine the role of CPEB in the later stages of gametogenesis, in oocyte maturation, and in progression through the zygote and cleavage stages. A northern blot showing expression of Mphosph6, using mRNAs isolated from various stages during the oocyte-to-embyro transition, illustrates the increased polyadenylation of this CPE-containing mRNA in the ovulated oocyte and zygote, and its deadenylation and degradation in the two-cell embryo (Fig. 3a). The cognate protein is synthesized normally in the ovulated oocyte and zygote (Fig. 3b) and is detected at different locations during the oocyte-to-embryo transition (Fig. 3c).

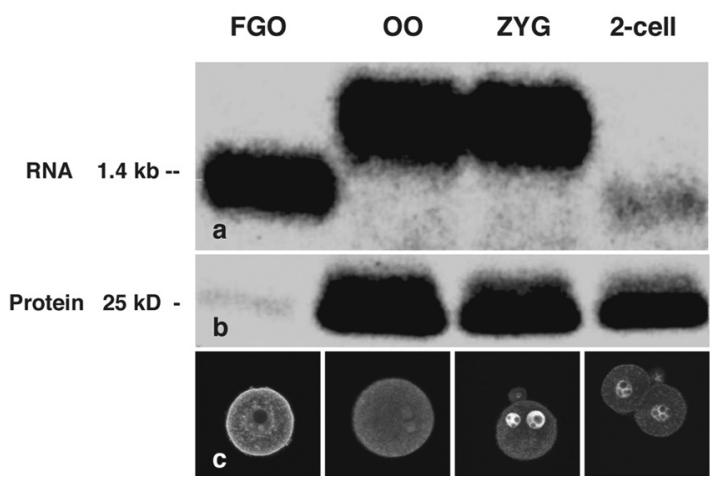

Figure 3. The maternal message of Mphosph6 is under translational control. A northern blot, immunoprecipitation, and immunofluorescence show the relationship between the polyadenylation status of the transcript and translation of the protein. (a) The transcript is deadenylated in the full-grown oocyte (FGO), adenylated in the ovulated oocyte (OO) and zygote (Zyg), and undergoes degradation in the two-cell-stage embryo (2-cell). (b) Adenylation leads to translation of the protein in the OO, zygote, and two-cell-stage embryo. (c) The protein detected in the FGO may have been accumulated during oocyte growth. Immunofluorescence shows changing localization of MPHOSPH6. AntiMPHOSPH6 guinea pig antiserum was a kind gift from Dr. Joanne M. Westendorf, Scripps Research Institute, La Jolla, California.

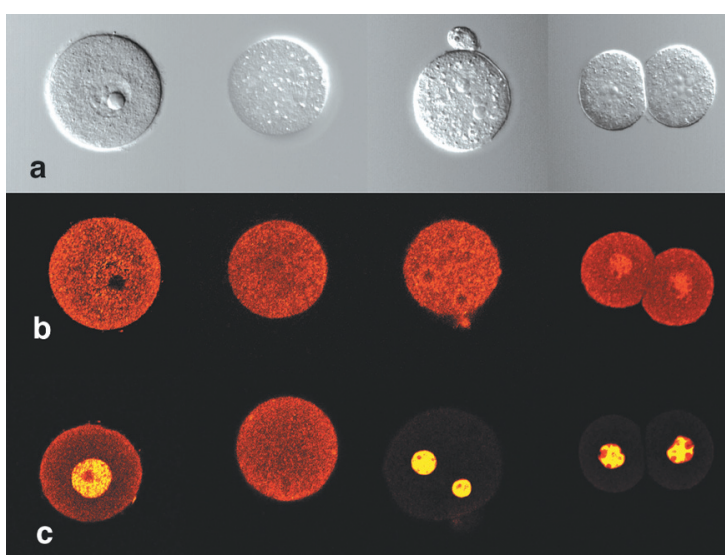

Figure 4. (a) DIC image of fully grown oocyte, ovulated oocyte, zygote, and two-cell-stage embryo; $(b)$ localization of a 19S proteasome subunit PSMC4, as detected by immunofluorescence; and $(c)$ localization of $20 \mathrm{~S}$ proteasome in the same developmental stages. (Modified, with permission, from Evsikov et al. 2004 [CS. Karger AG, Basel].)

Transcripts for several components of this translational control system are found in mouse oocytes and early embryos. CPEB, as well as Tacc2 and Tacc3, the mouse equivalents of maskin (Hao et al. 2002; Evsikov et al. 2004), are present. Other proteins, which bind to 3'UTR motifs and are known to be involved in mRNA stabilization in other species, such as Elavl1 and Elav12, are also abundantly expressed (Evsikov et al. 2004). While cytoplasmic polyadenylation is closely followed by or occurs in concert with translation, some fully polyadenylated mRNAs are not translated (Oh et al. 2000). This suggests the existence of still other mechanisms (Stutz et al. 1998) controlling translation. The picture of a versatile and complex temporal (and maybe spatial) control of mRNA utilization is slowly emerging.

Maternal mRNA storage and translation and modification of proteins made during oocyte growth are essential, temporally controlled initiation events. Just as these components are made available at the right time they should also be degraded in a temporal sequence. The RNA and protein degradation machinery and the molecules, which direct specific mRNAs and proteins to these degradation complexes, are present in the egg and early embryo (Evsikov et al. 2004). Both the 19S and 20S proteasome are present during the oocyte-to-embryo transition. The $20 \mathrm{~S}$ proteasome appears to be localized to the nucleus (Palmer et al. 1994), while components of the 19S proteasome are found in both the nucleus and the cytoplasm (Fig. 4) (Evsikov et al. 2004). The regulatory 19S subunit may function in transcriptional activation (Gonzalez et al. 2002). The importance of a functional proteasome system is evidenced by an experiment we performed in which fertilized mouse eggs were exposed to the proteasome inhibitor, lactacystin. Incubation of zygotes with lactacystin arrests development, while exposure of embryos shortly before the first division takes place has little or no effect (Table 1). This suggests that protein and RNA degradation is essential for the transition toward activation of the embryonic genome. 
Table 1. Effect of Proteasome Inhibitor Lactacystin on Preimplantation Development of Mouse Zygotes Isolated at Different Time Points

\begin{tabular}{|c|c|c|c|c|c|c|}
\hline \multirow[b]{3}{*}{$\begin{array}{l}\text { Start of in } \\
\text { vitro culture }\end{array}$} & \multicolumn{6}{|c|}{ Development in vitro } \\
\hline & \multicolumn{3}{|c|}{ Control } & \multicolumn{3}{|c|}{$10 \mu \mathrm{M}$ lactacystin } \\
\hline & $\begin{array}{c}\text { No. of } \\
\text { embryos }\end{array}$ & $\begin{array}{l}\text { No. of two-cell } \\
(40 \mathrm{~h})\end{array}$ & $\begin{array}{c}\text { No. of morulae } \\
(83 \mathrm{~h})\end{array}$ & $\begin{array}{c}\text { No. of } \\
\text { embryos }\end{array}$ & $\begin{array}{l}\text { No. of two-cell } \\
(40 \mathrm{~h})\end{array}$ & $\begin{array}{c}\text { No. of morulae } \\
(83 \mathrm{~h})\end{array}$ \\
\hline $18 \mathrm{~h}$ & 19 & 19 & 16 & 24 & 0 & 0 \\
\hline $20 \mathrm{~h}$ & 20 & 19 & 19 & 27 & 3 & 0 \\
\hline $22 \mathrm{~h}$ & 10 & 10 & 9 & 21 & 13 & 0 \\
\hline $24 \mathrm{~h}$ & 42 & 41 & 40 & 166 & 166 & 145 \\
\hline
\end{tabular}

All timing in hours post-hCG.

\section{RETROTRANSPOSONS AND microRNA}

A large part of the mammalian genome consists of interspersed repeats and transposable elements, whose role and effect on gene activity and function in genome evolution has been long debated (Britten 1997; Brosius 2003; van de Lagemaat et al. 2003; Kazazian 2004). Transcripts representing various classes of retrotransposons and repetitive sequences are abundantly represented (Fig. 5) in libraries of early mouse embryos (Evsikov et al. 2004; Peaston et al. 2004). The presence and transcription of various retrotransposons can have multiple, important effects. Activity of reverse transcriptase is essential in early embryos since development of one- to four-cell-stage embryos exposed to the reverse transcriptase inhibitor, neviparine, is arrested (Pittoggi et al. 2003).

In view of the high level of reverse transcriptase activity in the preimplantation period of development, particularly the late two-cell embryo (Evsikov et al. 2004), it is very likely that significant transposition of these viral genomes takes place. Retrotransposition of cellular gene transcripts may lead to integration and formation of pseudogenes in the two-cell-stage embryo. Indeed, two-cellstage-embryo-expressed genes are more likely to have three or more pseudogenes than genes expressed exclu-

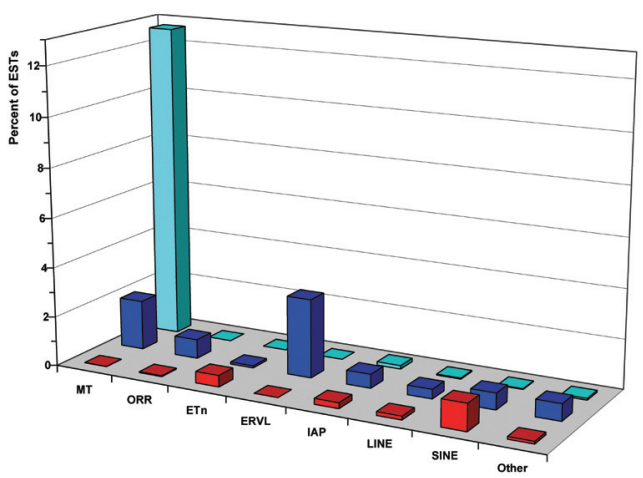

Figure 5. Differential expression of different classes of transposable elements in full-grown oocyte (light blue), two-cellstage embryo (dark blue), and blastocyst CDNA library (red). MT, Mouse transcript; ORR, Origin Region Repeat; Etn, Early Transposon; ERLV, Endogenous Retrovirus L; IAP, Intracysternal A-type Particles; LINE, Long Interspersed Nucleotide E1ement; SINE, Short Interspersed Nucleotide Element. sively in somatic cells (Evsikov et al. 2004; Zhang et al. 2004). Sequences derived from transposable elements can insert into cellular genes, creating mutations, or possibly novel regulatory elements, which could activate or silence targeted genes directly (Jordan et al. 2003; Han et al. 2004; Peaston et al. 2004; Pi et al. 2004), or through initiation of antisense transcripts (Kiyosawa et al. 2003; Han et al. 2004; Sémon and Duret 2004).

Transposable elements may also regulate gene expression and participate in chromatin remodeling via RNA interference (RNAi) mechanisms as shown in yeast (Schramke and Allshire 2003). While we do not know whether microRNAs are active in early embryos, embryonic stem cell-specific microRNAs have been described (Houbaviy et al. 2003). In addition, Dicerl, a gene essential for the RNAi pathway, is crucial for completion of early development; Dicer1-null-mutant embryos die soon after implantation (Bernstein et al. 2003). The absence of homozygous null-mutant females precludes analysis of the role of Dicer 1 during the oocyte-to-embryo transition. However, construction and conditional deletion of Dicer alleles in the oocyte will allow this important question to be addressed.

\section{CYTOPLASMIC LOCALIZATION AND POLARITY}

Accumulation of maternal mRNAs and proteins during oocyte growth is not sufficient for normal development; they have to be precisely localized in order to complete their function. The best and most detailed study of this phenomenon has been accomplished in Drosophila where mislocalization leads to abnormal development (van Eeden and St Johnston 1999). However, all metazoan organisms may require localized mRNA and protein to initiate development (for detailed reviews, see Etkin and Jeon 2001).

Does this principle apply to mammalian development? Because of the remarkable regulative capacity of the preimplantation mammalian embryo, which can develop normally after a substantial part of it has been removed or after the entire embryo has been duplicated by aggregation with another, it has been assumed that there is no cytoplasmic localization or polarity of developmental significance. In the last few years this view was challenged 
and it was suggested that the first cleavage division in mouse embryo is determined by the position of the second polar body, which was represented as the animal pole, thus defining the animal-vegetal (A-V) axis (Gardner 2001; Zernicka-Goetz 2002), and also, though there was disagreement on this point, by the sperm entry point (Piotrowska and Zernicka-Goetz 2001; Davies and Gardner 2002). In addition, though somewhat controversially (Davies and Gardner 2002), it was proposed that following the first cleavage the two blastomeres possess different developmental fates, and that the one that contains the sperm entry point and divides first will contribute predominantly to the inner cell mass of the blastocyst (Piotrowska and Zernicka-Goetz 2001; Piotrowska et al. 2001; Zernicka-Goetz 2002).

The ideas that landmarks in the egg and zygote can be used to predict the topography of the blastocyst, and possibly beyond, and that the axes of egg and zygote bear a spatial relationship with those of later embryos are intellectually pleasing. Furthermore, if documented, this would bring mammalian development into the conceptual fold of the general developmental pattern of other metazoans. However, our recent results cast serious doubt on the notion that the first cleavage plane is predetermined and that the $\mathrm{A}-\mathrm{V}$ axis of the mouse egg exists in any functional predictive sense (Hiiragi and Solter 2004). Using time-lapse photography we have shown that the second polar body, the putative marker of the animal pole, moves extensively before and after cleavage, and that it always ends up within the cleavage furrow. Thus, the plane of the first cleavage determines the final location of the second polar body and not the other way around. In addition, we documented that as the two pronuclei move from periphery of the zygote toward the center, they finally firmly appose before nuclear membrane breakdown. The plane of apposition coincides with the plane of the first cleavage and is independent of the position of the second polar body or the sperm entry point (Fig. 6).

In the majority of cases both pronuclei follow the most direct path toward the center with the result that the plane of apposition and the plane of the first cleavage bisect the shortest arc between the second polar body and the sperm entry point (Fig. 6a-d). However, in some cases the

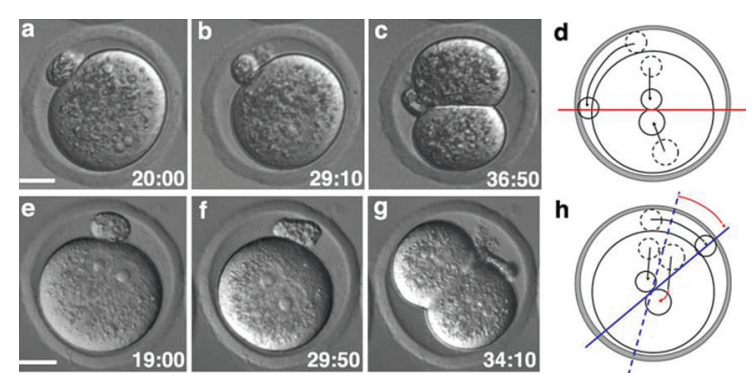

Figure 6. The first cleavage plane is specified by the topology of the two apposing pronuclei in the egg center. $(a-c, e-g)$ Sequence of events for an embryo of each type. $(a, e)$ Pronuclei formation. $(b, f)$ The two pronuclei apposing in the center just before pronuclear membrane breakdown, thus defining the first cleavage plane. $(c, g)$ Nuclei formed at the two-cell stage. In each frame, time is given in hours:minutes after hCG injection. Scale bars, 20 $\mu \mathrm{m}$. $(d, h)$ Schematic models of first cleavage plane specification in each type of embryo (corresponding to the types in $a-c$ and in $e-g$, respectively). Note that in an embryo of the type shown in $e, f$, the first cleavage plane is specified by the two pronuclei rotating after their apposition in the egg center. Broken lines, the initial position of the second polar body and pronuclei prior to reaching the final position before cleavage (represented by a solid line); broken blue line, the presumed cleavage plane had the pronuclei not rotated; red arrows, the rotation of the pronuclei and resulting rotation of the cleavage plane.

pronuclei rotate once they reach the center of the egg. In those cases the plane of division is again determined by the final plane of apposition (Fig. 6e-h). It is important to note that, in the examples shown, the plane of division, instead of coinciding with the plane, which passes through the animal pole (Gardner 2001; Piotrowska and Zernicka-Goetz 2001; Piotrowska et al. 2001; ZernickaGoetz 2002; Gardner and Davies 2003) and the sperm entry point (Piotrowska and Zernicka-Goetz 2001; Zernicka-Goetz 2002), is actually perpendicular to it. However, in all cases observed it is predicted by the apposition of the two pronuclei (Hiiragi and Solter 2004).

It seems that in this unique biological situation, when there are two nuclei within a round cell, their apposition signals the organization of the cytoskeleton and the mitotic spindle to insure the correct positioning and separation of chromatids, i.e., the plane of apposition corre-
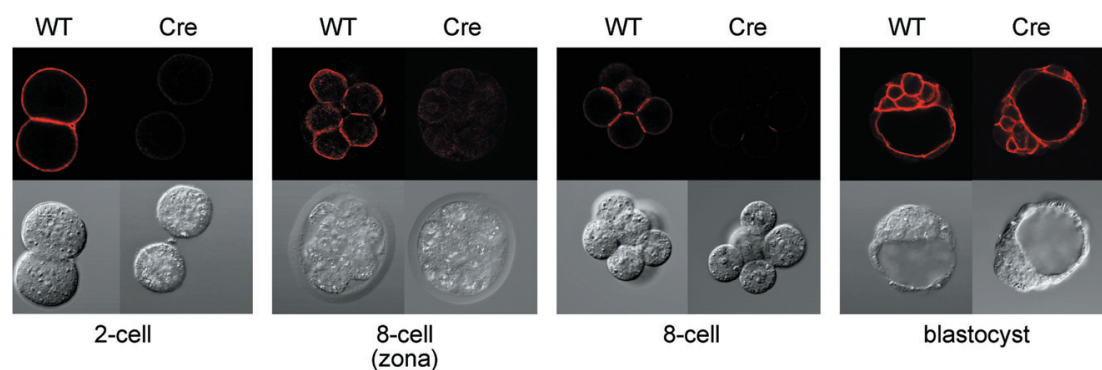

Figure 7. Embryos lacking maternal E-cadherin develop normally in spite of the lack of blastomere adhesion during early cleavages. E-cadherin, detected using a polyclonal antibody, is visible on the blastomere surface of a control (WT) two-cell-stage embryo, eightcell-stage embryo, and blastocyst, but not on the blastomere surface of two-cell-stage and eight-cell-stage embryos lacking maternal E-cadherin (Cre, ZP3 cre removal of floxed E-cadherin during oocyte growth). Protein expressed from the paternal allele is visible at the blastocyst stage. 8-cell (zona) represents an eight-cell-stage embryo stained with the zona pellucida still surrounding it. Bottom panel, the DIC images. 
sponds to the future metaphase plate (Hiiragi and Solter 2004). According to our results the first cleavage plane has no observable relationship with any morphological feature of the egg and zygote, thus the idea that the A-V axis of the egg relates to the future axes of the embryo cannot be supported. Whether the plane of the first cleavage is related to the plane of bilateral symmetry of the blastocyst, or its embryonic-abembryonic axis, remains to be determined. However, conditional deletion of Ecadherin in the oocyte (de Vries et al. 2000, 2004), which eliminates all intracellular contacts between blastomeres from the two-cell until the 16-cell stage, does not affect the development of these embryos (Fig. 7). Although the blastomeres are kept together within the zona, the individual cells are not fixed in place until compaction, in this case at the 16-cell stage, making a fixed relationship between the first cleavage plane and the position of cells in the blastocyst even less likely.

\section{CONCLUSIONS}

Early mammalian development is dependent on a wide range of stored epigenetic information. The DNA of sperm and egg is modified by methylation and particular genes are either paternally or maternally imprinted, which determines their subsequent expression pattern. The chromatin of the germ cells contains unique proteins, specially modified histones and protamines, which insure transcriptional silence, and these proteins must be modified or replaced for the embryonic genome to become active. Maternal mRNAs and proteins, made during oogenesis, are selectively utilized to insure the proper transition from the oocyte to the embryo. Various mechanisms regulate correct, timely translation and degradation of stored maternal mRNAs as well as posttranslational modifications and degradation of maternal proteins. The possible role of transposable elements and microRNAs during early development is just beginning to be explored. At this writing it appears highly unlikely that polarity exists in the mammalian egg and zygote or that the first cleavage plane determines bilateral symmetry in the blastocyst.

\section{ACKNOWLEDGMENTS}

This work was supported by CJ Martin Fellowship 007150 awarded by the NHMRC of Australia (A.E.P.), The Lalor Foundation (A.V.E.), Howard Hughes Memorial Institute (J.M.), The National Institutes of Health P20 RR018789 (W.N.dV.), HD37102, P30 CA 34196, The National Science Foundation EPS-0132384 (B.B.K.), and the Max Planck Society (D.S., T.H.). The authors are grateful to Dr. Joanne M. Westendorf for her gift of antibody to M Phase Phosphoprotein 6.

\section{REFERENCES}

Bernstein E., Kim S.Y., Carmell M.A., Murchison E.P., Alcorn H., Li M.Z., Mills A.A., Elledge S.J., Anderson K.V., and Hannon G.J. 2003. Dicer is essential for mouse development. Nat. Genet. 35: 215.

Bouniol C., Nguyen E., and Debey P. 1995. Endogenous transcription occurs at the 1-cell stage in the mouse embryo. Exp.
Cell Res. 218: 57.

Britten R.J. 1997. Mobile elements inserted in the distant past have taken on important functions. Gene 205: 177.

Brosius J. 2003. The contribution of RNAs and retroposition to evolutionary novelties. Genetica 118: 99.

Darnell R.B. 2002. RNA logic in time and space. Cell 110: 545.

Davies T.J. and Gardner R.L. 2002. The plane of first cleavage is not related to the distribution of sperm components in the mouse. Hum. Reprod. 17: 2368.

de Vries W.N., Binns L.T., Fancher K.S, Dean J., Moore R., Kemler R., and Knowles B.B. 2000. Expression of Cre-recombinase in mouse oocytes: A means to study maternal effect genes. Genesis 26: 110 .

de Vries W.N., Evsikov A.V., Haac B.E., Fancher K.S., Holbrook A.E., Kemler R., Solter D., and Knowles B.B. 2004. Maternal $\beta$-catenin and E-cadherin in mouse development. Development 131: 4435.

Etkin L.D. and Jeon K.W., eds. 2001. Cell lineage specification and patterning of the embryo. Academic Press, San Diego, California.

Evsikov A.V., de Vries W.N., Peaston A.E., Radford E.E., Fancher K.S., Chen F.H., Blake J.A., Bult C.J., Latham K.E., Solter D., and Knowles B.B. 2004. Systems biology of the 2cell mouse embryo. Cytogenet. Genome Res. 105: 240.

Gao S., Chung Y.G., Parseghian M.H., King G.J., Adashi E.Y., and Latham K.E. 2004. Rapid H1 linker histone transitions following fertilization or somatic cell nuclear transfer: Evidence for a uniform developmental program in mice. Dev. Biol. 266: 62 .

Gardner R.L. 2001. The initial phase of embryonic patterning in mammals. In Cell lineage specification and patterning of the embryo (ed. L.D. Etkin and K.W. Jeon), p. 233. Academic Press, San Diego, California.

Gardner R.L. and Davies T.J. 2003. The basis and significance of pre-patterning in mammals. Philos. Trans. R. Soc. Lond. B Biol. Sci. 358: 1331.

Gonzalez F., Delahodde A., Kodadek T., and Johnston S.A. 2002. Recruitment of a 19 S proteasome subcomplex to an activated promoter. Science 296: 548.

Grewal S.I.S. and Moazed D. 2003. Heterochromatin and epigenetic control of gene expression. Science 301: 798.

Hamatani T., Carter M.G., Sharov A.A., and Ko M.S.H. 2004. Dynamics of global gene expression changes during mouse preimplantation development. Dev. Cell 6: 117

Han J.S., Szak S.T., and Boeke J.D. 2004. Transcriptional disruption by the L1 retrotransposon and implications for mammalian transcriptomes. Nature 429: 268.

Hao Z., Stoler M.H., Sen B., Shore A., Westbrook A., Flickinger C.J., Herr J.C., and Coonrod S.A. 2002. TACC3 expression and localization in the murine egg and ovary. Mol. Reprod. Dev. 63: 291.

Hiiragi T. and Solter D. 2004. First cleavage plane of the mouse egg is not predetermined but defined by the topology of the two apposing nuclei. Nature 429: 1360.

Hodgman R., Tay J., Mendez R., and Richter J.D. 2001. CPEB phosphorylation and cytoplasmic polyadenylation are catalyzed by the kinase IAK1/Eg2 in maturing mouse oocytes. Development 128: 2815.

Houbaviy H.B., Murray M.F., and Sharp P.A. 2003. Embryonic stem cell-specific microRNAs. Dev. Cell 5: 351.

Jordan I.K., Rogozin I.B., Glazko G.V., and Koonin E.V. 2003. Origin of a substantial fraction of human regulatory sequences from transposable elements. Trends Genet. 19: 68.

Kaneko-Ishino T., Kohda T., and Ishino F. 2003. The regulation and biological significance of genomic imprinting in mammals. J. Biochem. 133: 699.

Kazazian H.H., Jr. 2004. Mobile elements: Drivers of genome evolution. Science 303: 1626.

Kiyosawa H., Yamanaka I., Osato N., Kondo S., and Hayashizaki Y. 2003. Antisense transcripts with FANTOM2 clone set and their implications for gene regulation. Genome Res. 13: 1324.

Knowles B.B., Evsikov A.V., de Vries W.N., Peaston A.E., and Solter D. 2003. Molecular control of the oocyte to embryo 
transition. Philos. Trans. R. Soc. Lond. B Biol. Sci. 358: 1381

Kuzmichev A., Nishioka K., Erdjument-Bromage H., Tempst P., and Reinberg D. 2002. Histone methyltransferase activity associated with a human multiprotein complex containing the Enhancer of Zeste protein. Genes Dev. 16: 2893.

Li E. 2002. Chromatin modification and epigenetic reprogramming in mammalian development. Nat. Rev. Genet. 3: 662

Liu H., Kim J.-M., and Aoki F. 2004. Regulation of histone H3 lysine 9 methylation in oocytes and early pre-implantation embryos. Development 131: 2269.

McGrath J. and Solter D. 1984. Completion of mouse embryogenesis requires both the maternal and paternal genomes. Cell 37: 179 .

Oh B., Hwang S.-Y., McLaughlin J., Solter D., and Knowles B.B. 2000. Timely translation during the mouse oocyte-toembryo transition. Development 127: 3795 .

Ostermeier G.C., Miller D., Huntriss J.D., Diamond M.P., and Krawetz S.A. 2004. Delivering spermatozoan RNA to the oocyte. Nature 429: 154.

Palmer A., Mason G.G., Paramio J.M., Knecht E., and Rivett A.J. 1994. Changes in proteasome localization during the cell cycle. Eur. J. Cell Biol. 64: 163.

Peaston A.E., Evsikov A.V., Graber J.H., de Vries W.M., Holbrook A.E., Solter D., and Knowles B.B. 2004. Retrotransposons regulate host genes in mouse oocytes and preimplantation embryos. Dev. Cell 7: 597.

Pi W., Yang Z., Wang J., Ruan L., Yu X., Ling J., Krantz S., Isales C., Conway S.J., Lin S., and Tuan D. 2004. The LTR enhancer of ERV-9 human endogenous retrovirus is active in oocytes and progenitor cells in transgenic zebrafish and humans. Proc. Natl. Acad. Sci. 101: 805.

Piotrowska K. and Zernicka-Goetz M. 2001. Role for sperm in spatial patterning of the early mouse embryo. Nature 409: 517.

Piotrowska K., Wianny F., Pedersen R.A., and Zernicka-Goetz M. 2001. Blastomeres arising from the first cleavage division have distinguishable fates in normal mouse development. Development 128: 3739 .

Pittoggi C., Sciamanna I., Mattei E., Beraldi R., Lobascio A.M., Mai A., Quaglia M.G., Lorenzini R., and Spadafora C. 2003. Role of endogenous reverse transcriptase in murine early embryo development. Mol. Reprod. Dev. 66: 225.

Reik W. and Walter J. 2001a. Genomic imprinting: Parental influence on the genome. Nat. Rev. Genet. 2: 21

2001b. Evolution of imprinting mechanisms: The battle of the sexes begins in the zygote. Nat. Genet. 27: 255.

Reik W., Santos F., Mitsuya K., Morgan H., and Dean W. 2003. Epigenetic asymmetry in the mammalian zygote and early embryo: Relationship to lineage commitment? Philos. Trans. R. Soc. Lond. B Biol. Sci. 358: 1403.

Richter J.D. 1999. Cytoplasmic polyadenylation in development and beyond. Microbiol. Mol. Biol. Rev. 63: 446.

Rothstein J.L., Johnson D., DeLoia J.A., Skowronski J., Solter D., and Knowles B.B. 1992. Gene expression during preimplantation mouse development. Genes Dev. 6: 1190.

Santos F., Hendrich B., Reik W., and Dean W. 2002. Dynamic reprogramming of DNA methylation in the early mouse embryo. Dev. Biol. 241: 172.

Schramke V. and Allshire R. 2003. Hairpin RNAs and retrotransposon LTRs effect RNAi and chromatin-based gene silencing. Science 301: 1069.

Sémon M. and Duret L. 2004. Evidence that functional tran- scription units cover at least half of the human genome. Trends Genet. 20: 229.

Sharov A.A., Piao Y., Matoba R., Dudekula D.B., Qian Y., VanBuren V., Falco G., Martin P.R., Stagg C.A., Bassey U.C., Wang X., Carter M.G., Hamatani T., Aiba K., Akutsu H., Sharova L., Tanaka T.S., Kimber W.L., Yoshikawa T., Jaradat S.A., Pantano S., Nagaraja R., Boheler K.R., Taub D., Hodes R.J., Longo D.L., Schlessinger D., Keller J., Klotz E., Kelsoe G., Umezawa A., Vescovi A.L., Rossant J., Kunath T., Hogan B.L.M., Curci A., D’Urso M., Kelso J., Hide W., and Ko M.S.H. 2003. Transcriptome analysis of mouse stem cells and early embryos. PLoS Biol. 1: 410.

Solter D. and Knowles B.B. 1999. Spatial and temporal control of maternal message utilization. In Development: Genetics, epigenetics and environmental regulation (ed. V.E.A. Russo et al.), p. 389. Springer, Berlin, Germany.

Solter D., de Vries W.N., Evsikov A.V., Peaston A.E., Chen F.H., and Knowles B.B. 2002. Fertilization and activation of the embryonic genome. In Mouse development. Patterning, morphogenesis, and organogenesis (ed. J. Rossant and P.P.L. Tam), p. 5. Academic Press, San Diego, California.

Stebbins-Boaz B., Cao Q., de Moor C.H., Mendez R., and Richter J.D. 1999. Maskin is a CPEB-associated factor that transiently interacts with elF-4E. Mol. Cell 4: 1017.

Strickland S., Huarte J., Belin D., Vassalli A., Rickles R., and Vassalli J.-D. 1988. Antisense RNA directed against the 3' noncoding region prevents dormant mRNA activation in mouse oocytes. Science 241: 680.

Stutz A., Conne B., Huarte J., Gubler P., Volkel V., Flandin P., and Vassalli J.-D. 1998. Masking, unmasking, and regulated polyadenylation cooperate in the translational control of a dormant mRNA in mouse oocytes. Genes Dev. 12: 2535.

Surani M.A.H., Barton S.C., and Norris M.L. 1984. Development of reconstituted mouse eggs suggests imprinting of the genome during gametogenesis. Nature 308: 548 .

Tay J. and Richter J.D. 2001. Germ cell differentiation and synaptonemal complex formation are disrupted in CPEB knockout mice. Dev. Cell 1: 201.

Teranishi T., Tanaka M., Kimoto S., Ono Y., Miyakoshi K., Kono T., and Yoshimura Y. 2004. Rapid replacement of somatic linker histones with the oocyte-specific linker histone H1 foo in nuclear transfer. Dev. Biol. 266: 76.

van de Lagemaat L.N., Landry J.-R., Mager D.L., and Medstrand P. 2003. Transposable elements in mammals promote regulatory variation and diversification of genes with specialized functions. Trends Genet. 19: 530.

van Eeden F. and St Johnston D. 1999. The polarisation of the anterior-posterior and dorsal-ventral axes during Drosophila oogenesis. Curr. Opin. Genet. Dev. 9: 396.

Wang Q.T., Piotrowska K., Ciemerych M.A., Milenkovic L., Scott M.P., Davis R.W., and Zernicka-Goetz M. 2004. A genome-wide study of gene activity reveals developmental signaling pathways in the preimplantation mouse embryo. Dev. Cell 6: 133 .

Wilkins J.F. and Haig D. 2003. What good is genomic imprinting: The function of parent-specific gene expression. Nat. Rev. Genet. 4: 359.

Zernicka-Goetz M. 2002. Patterning of the embryo: The first spatial decisions in the life of a mouse. Development 129: 815 .

Zhang Z., Carriero N., and Gerstein M. 2004. Comparative analysis of processed pseudogenes in the mouse and human genomes. Trends Genet. 20: 62. 


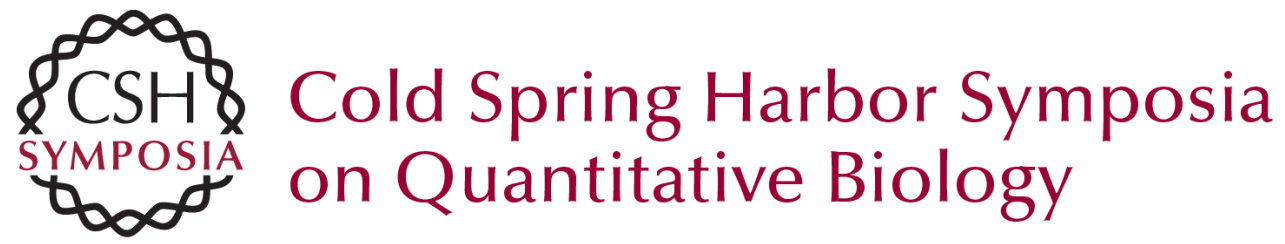

\section{Epigenetic Mechanisms in Early Mammalian Development}

D. SOLTER, T. HIIRAGI, A.V. EVSIKOV, et al.

Cold Spring Harb Symp Quant Biol 2004 69: 11-18

Access the most recent version at doi:10.1101/sqb.2004.69.11

References This article cites 57 articles, 16 of which can be accessed free at: http://symposium.cshlp.org/content/69/11.full.html\#ref-list-1

\section{License}

Email Alerting Receive free email alerts when new articles cite this article - sign up in Service the box at the top right corner of the article or click here. 